\title{
Changes in glutamate homeostasis cause retinal degeneration in Royal College of Surgeons rats
}

\author{
KANG LIU, YI WANG, ZHENGQIN YIN, CHUANHUANG WENG and YUXIAO ZENG \\ Southwest Eye Hospital, Southwest Hospital, The Third Military Medical University, Chongqing 400038, P.R. China
}

Received September 24, 2012; Accepted November 9, 2012

DOI: $10.3892 / \mathrm{ijmm} .2013 .1297$

\begin{abstract}
The aim of the present study was to investigate glutamate homeostasis in retinal degeneration-induced changes and the potential mechanisms of glutamate-mediated excitotoxicity in a rat model. The expression of vesicular glutamate transporter-1 (VGLUT-1) and protein kinase $\mathrm{C} \alpha(\mathrm{PKC} \alpha)$ in wild-type and Royal College of Surgeons (RCS) rat retinas, at postnatal Day 15 (P15), P30, P60 and P90, were detected using quantitative real-time polymerase chain reaction and immunohistochemistry. The levels of glutamine synthetase (GS) and L-glutamate/L-aspartate transporter (GLAST) were evaluated by western blotting. Compared with wild-type rats, outer nuclear layer thickness was significantly thinner and VGLUT-1 expression was upregulated in a time-dependent pattern in RCS rats. The ratio of VGLUT-1 to PKC $\alpha$ in RCS rats peaked at $\mathrm{P} 60(\mathrm{p}<0.01)$ and subsequently decreased by P90 ( $<<0.01)$, while it remained constant in wild-type rats. The expression of GS increased gradually from P30 to P90 in RCS rats $(\mathrm{p}<0.01)$, while it remained constant in wild-type rats at various time-points. No significant difference in GLAST expression was found between RCS and wild-type rats at all stages of retinal degeneration. Our results confirm the occurrence of glutamate-mediated excitotoxicity to RCS rat retinas and provide an experimental foundation for safeguarding the remnant visual function in retinal degenerative disorders.
\end{abstract}

\section{Introduction}

Retinitis pigmentosa (RP) is one of the leading causes of vision impairment and blindness affecting millions of people worldwide $(1,2)$. The Royal College of Surgeons (RCS) rat is a widely used animal model to study retinal degeneration diseases and the process of retinal remodeling; it inherits a

Correspondence to: Professor Yi Wang or Professor Zhengqin Yin, Southwest Eye Hospital, Southwest Hospital, The Third Military Medical University, Chongqing 400038, P.R. China

E-mail:wangyieye@yahoo.com.cn

E-mail: qinzyin@yahoo.com.cn

Key words: glutamate, retinal degeneration, Royal College of Surgeons rats, glutamine synthetase, L-glutamate/L-aspartate transporter, vesicular glutamate transporter-1, protein kinase $\mathrm{C} \alpha$ null mutation in MER, a member of the Ax1/Mer/Tyro3 receptor tyrosine kinase family gene (MERTK) of the retinal pigment epithelium (RPE) (3). This mutation results in RPE dysfunction and photoreceptor degeneration (1). Congenic strains of RCS rats, genetically similar to the inbred RCS strain, were produced in the 1970s and early 1980s (4,5). These strains comprise: i) pink-eyed rats that are wild-type $(+/+)$ at the retinal dystrophy locus (rdy locus; the strain is designated as $\mathrm{RCS}-\mathrm{rdy}^{+}$) and serve as control animals for the pink-eyed dystrophic, inbred RCS strain; ii) pigmented (black-hooded) dystrophic rats (the strain is designated as $\mathrm{RCS}-\mathrm{p}^{+}$); and iii) pigmented, non-dystrophic rats for use as normal controls for the pigmented dystrophic rat (the strain is designated as RCS-rdy ${ }^{+} \mathrm{p}^{+}$.

Mammalian retinal degeneration is involved in extensive structural changes in retinal neurons (6), loss of bipolar (7) and ganglion cells (8), heterotopic migration of neurons (9), and the presence of ectopic neurites and microneuromas (10). The action potentials of retinal ganglion cells were reduced in amplitude and frequency during retinal degeneration, although morphological changes of retina ganglion cells are not apparent (11). To date, the mechanism(s) responsible for retinal neuronal dysfunction and loss of retinal neurons at the terminal stage of degeneration remain unclear.

Glutamate is a major excitatory neurotransmitter in the vertebrate retina, responsible for the input of visual signals (12). In the normal state, photoreceptors (rods and cones) and bipolar cells release glutamate, which is toxic to retinal cells $(13,14)$, glial L-glutamate/L-aspartate transporter (GLAST), which is expressed in the membrane of Müller cells, and glutamine synthetase (GS), which is expressed in the cytoplasm of Müller cells to maintain the requisite glutamate homeostasis $(15,16)$. The glutamate in retinal neurons is bound with vesicular glutamate transporter-1 (VGLUT-1) reserved in the synaptic vesicle and is released during neuronal excitation. After being released by neurons, free glutamate in the extracellular space is bound with GLAST and taken up by Müller cells. Glutamate is then transformed to glutamine by GS in Müller cells. Subsequently, glutamine is released by Müller cells to the extracellular space, and the glutamatergic neurons uptake glutamine in order to synthesize glutamate. Finally, the glutamate reserves in the synaptic vesicle bind with VGLUT-1. As a result, finely tuned glutamate release, uptake, and degradation are essential for avoiding neurotoxicity and transmitting normal signals from photoreceptors to bipolar and ganglion cells. 
In the present study, we investigated the expressions of key factors involved in glutamate metabolism in the degenerating RCS rat retina. Both mRNA and protein levels of VGLUT-1, protein kinase $\mathrm{C} \alpha(\mathrm{PKC} \alpha), \mathrm{GS}$, and GLAST were evaluated by quantitative real-time polymerase chain reaction (qPCR), immunohistochemistry, and western blot analyses.

\section{Materials and methods}

Animals. All experiments were conducted with the approval of the Animal Ethics Committee of the Southwest Hospital, Chongqing, China, and the ethics guidelines set forth by the Laboratory Animal Care and Use Committee of the Association for Research in Vision and Ophthalmology were followed. All efforts were made to minimize animal suffering and to use the fewest number of animals in the study.

Black-eyed dystrophic strain (RCS- $\mathrm{p}^{+}$) and black-eyed nondystrophic control strain $\left(\mathrm{RCS}-\mathrm{rdy}^{+} \mathrm{p}^{+}\right)$rats were anesthetized by intraperitoneal injection of $10 \%$ chloral hydrate, after which both eyes were enucleated. Animals were then euthanized with an overdose of anesthetic. Retinas from both groups of rats were analyzed at four scheduled time-points: postnatal Days 15 (P15), P30, P60 and P90. At least six rat retinas were used for each time-point.

Immunohistochemistry. Eyes for immunohistochemical analysis were fixed in $4 \%$ paraformaldehyde in $0.1 \mathrm{M}$ phosphatebuffered saline (PBS) for $2 \mathrm{~h}$ at $4^{\circ} \mathrm{C}$, and then cryoprotected in $30 \%$ sucrose in $0.1 \mathrm{M}$ PBS for $1-2$ days at $4^{\circ} \mathrm{C}$. Eyecups were embedded with optimum cutting temperature (OCT) compound prior to cryostat sectioning at $10 \mu \mathrm{M}$, and they were stored at $-80^{\circ} \mathrm{C}$ for subsequent use. Frozen tissue sections were initially thawed and rehydrated in 0.01 M PBS (pH 7.2). Following incubation in 5\% normal goat serum (Jackson ImmunoResearch, USA) for $1 \mathrm{~h}$ at room temperature, sections were incubated with mouse monoclonal PKC $\alpha$ antibody (1:500) (Abcam, UK) overnight at $4^{\circ} \mathrm{C}$. Following three rinses (5 min each) with PBS, fluorescein isothiocyanate (FITC)-conjugated goat anti-mouse IgG antibody (1:200) (Jackson ImmunoResearch) was added to the slides and the slides were incubated for $1 \mathrm{~h}$ at room temperature. Finally, 4',6-diamidino-2-phenylindole (DAPI) staining was performed for labeling cell nuclei. After several rinses with PBS, the sections were covered with coverslips.

Quantitative real-time polymerase chain reaction. After enucleating, retinas were isolated and frozen in liquid nitrogen until use. For qPCR analysis, total RNA was isolated with TRIzol reagent, according to the manufacturer's instructions. After contaminated DNAs were removed using the TURBO DNA-free ${ }^{\mathrm{TM}}$ kit (Applied Biosystems), cDNAs were synthesized from $2 \mu \mathrm{g}$ of total RNA using the PrimeScript ${ }^{\mathrm{TM}}$ RT Reagent kit (Takara Bio, Inc., Japan) in $20 \mu \mathrm{l}$ of reaction mixture. qPCR was carried out using the Bio-Rad 5-Color System (Bio-Rad, USA). All primers were designed online using SciTools software, Integrated DNA Technologies, Inc., (IDT). The sequences are listed in Table I. The expression change of a target gene in RCS rats relative to control rats was calculated as follows: fold change $=2^{-(\Delta \mathrm{CT}, \mathrm{Tg}-\Delta \mathrm{CT}, \mathrm{control})}$. The following PCR scheme was used: $5 \mathrm{~min}$ at $94^{\circ} \mathrm{C},\left(30 \mathrm{sec}\right.$ at $94^{\circ} \mathrm{C}, 30 \mathrm{sec}$ at $63^{\circ} \mathrm{C}, 30 \mathrm{sec}$ at $\left.72^{\circ} \mathrm{C}\right)$ for 35 cycles, $10 \mathrm{~min}$ at $72^{\circ} \mathrm{C}$, and then $4^{\circ} \mathrm{C}$ thereafter.
Western blot analysis. For detection of GLAST and GS protein expression levels, RCS rat retinas from each group were homogenized in ice-cold radio-immunoprecipitation assay (RIPA) lysis buffer [50 mM of Tris-HCl buffer ( $\mathrm{pH} 7.4$ ), $150 \mathrm{mM} \mathrm{NaCl}$, $1 \%$ Triton $\mathrm{X}-100,1 \%$ sodium deoxycholate, $0.1 \%$ SDS, $1 \mathrm{mM}$ sodium orthovanadate, $25 \mathrm{mM}$ sodium fluoride, $1 \mathrm{mM}$ EDTA, and $1 \mu \mathrm{g} / \mathrm{ml}$ leupeptin]. Homogenates were then centrifuged at $12,000 \times \mathrm{g}$ for $5 \mathrm{~min}$ at $4^{\circ} \mathrm{C}$, and the clear supernatants were stored at $-80^{\circ} \mathrm{C}$ until use. Protein concentrations were determined using the Bicinchoninic Acid kit (Beyotime Institute of Biotechnology, China). Samples (50 $\mu \mathrm{g}$ of protein/lane) were loaded and electrophoresed on $12 \%$ SDS-polyacrylamide gels (SDS-PAGE) for $40 \mathrm{~min}$ at $120 \mathrm{~V}$. Proteins were then transferred to nitrocellulose (NC) membranes for $70 \mathrm{~min}$ at $120 \mathrm{~V}$. After transferring, the NC membranes were blocked with blocking solution containing Tris-buffered saline, $0.1 \%$ Tween-20 (TBST), and 5\% free-fat milk for $1 \mathrm{~h}$ at room temperature. Blots were then washed three times ( 5 min each) with TBST and incubated with rabbit polyclonal GLAST antibody or GS antibody (Abcam) overnight at $4^{\circ} \mathrm{C}$. After washing, all membranes were again incubated with mouse monoclonal GAPDH antibody for $1 \mathrm{~h}$ at room temperature. Subsequently, all membranes were incubated with the following secondary antibodies: IRDye 680-labeled donkey anti-rabbit IgG and IRDye 800-labeled donkey anti-mouse IgG (LI-COR Biosciences, Lincoln, NE, USA) in turn for $1 \mathrm{~h}$ at room temperature with shaking. Membranes were rinsed between incubations. Finally, NC membranes were scanned for GLAST, GS and GAPDH bands using the Odyssey infrared imaging system with Odyssey Application software V1.2.15. Densitometry ratios between GLAST and GAPDH, and GS and GAPDH were obtained to semi-quantify the relative levels of GLAST and GS.

Statistical analysis. All data are presented as the means \pm standard error (SE). Data were evaluated by one-way analysis of variance (ANOVA) and the LSD-q test, with post hoc statistical analysis for the same group, and t-tests for comparing means between experimental and control groups at the same time-points. Values of $\mathrm{p}<0.05$ were considered to indicate statistically significant differences.

\section{Results}

Changes in outer nuclear layer thickness during retinal degeneration. Immunofluorescence staining showed that the thickness of the outer nuclear layer (ONL) in control group retinas remained unchanged at all time-points (Fig. 1A-D). In the RCS rats, the ONL thickness at P15 was similar to that of the control group, but a thinner ONL was observed at P30. In addition, the number of photoreceptor cells in RCS rats was decreased at P60, and disappeared by P90 (Fig. 1E-H). Meanwhile, in RCS rats, a significant fibrotic glial seal layer (FGSL) between the ONL and outer plexiform layer (OPL) had gradually formed. There were no significant differences in the mean thickness of the inner nuclear layer (INL) between the two groups.

Changes in glutamate release during retinal degeneration. qPCR results showed that PKC $\alpha$ and VGLUT-1 mRNA were present in the retinas. No significant difference was found at 
Table I. qPCR primers used in the present study.

\begin{tabular}{lll}
\hline Gene $($ rat $)$ & \multicolumn{1}{c}{ Forward primer } & \multicolumn{1}{c}{ Reverse primer } \\
\hline$P K C \alpha(144 \mathrm{bp})$ & GGGGGAAAGGGATGTCAGAG & CTGCCCTCGTGTGAAGAACTT \\
$V G L U T-1(122 \mathrm{bp})$ & TGCTGCTGGTGGTCGGATAC & AGGGGCGATGTCCAAGTGGT \\
GAPDH $(158 \mathrm{bp})$ & GCCCATCACCATCTTCCAGGAG & GAAGGGGCGGAGATGATGAC
\end{tabular}

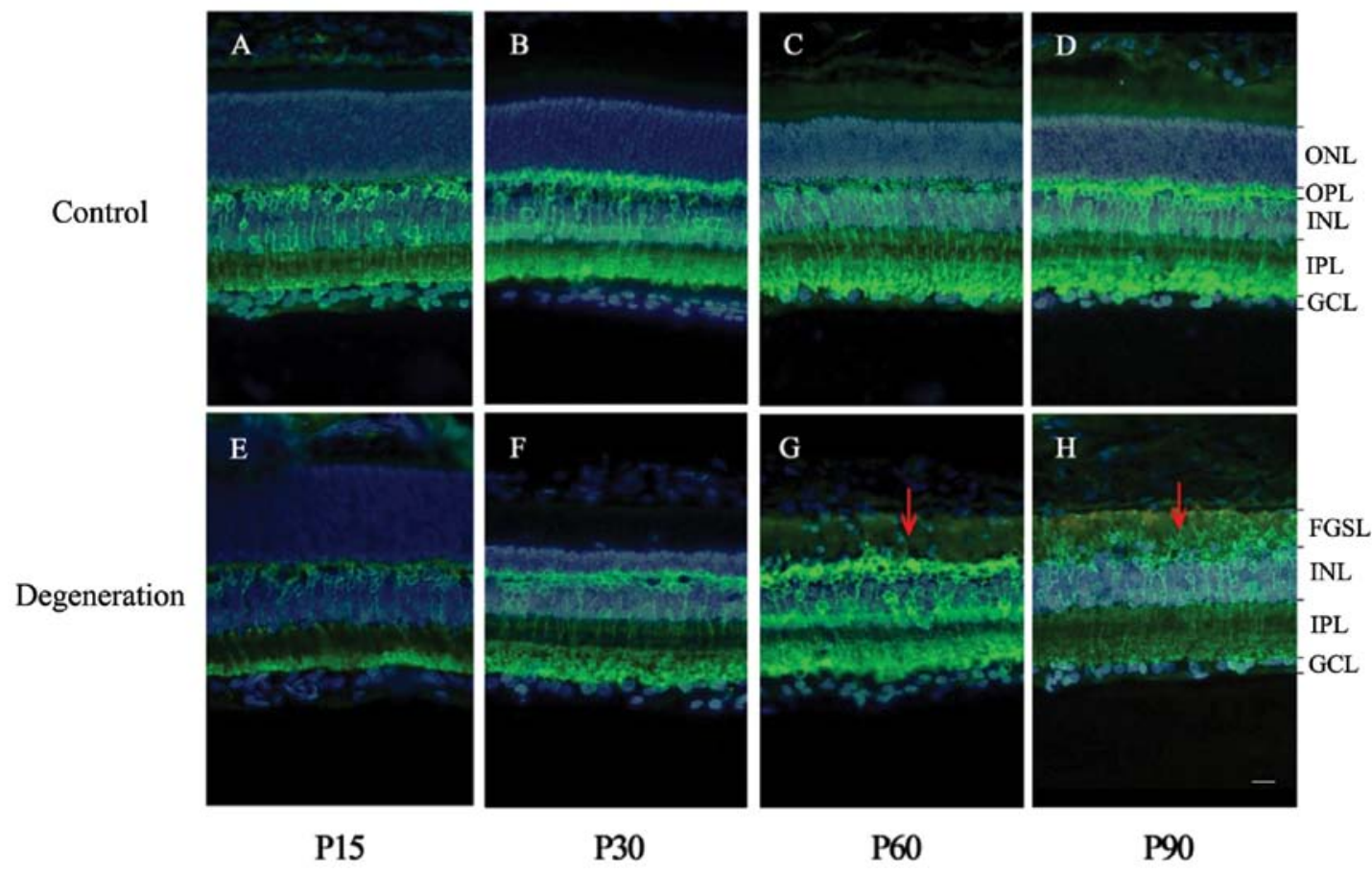

Figure 1. PKC $\alpha$ immunofluorescence staining of rat retinas in RCS and control rats. PKC $\alpha$ (green) labeling shows rod bipolar cells, including dendrites, soma, and axon terminals. DAPI (blue) labeling shows whole cell nuclei in the retina. (A-D) Digital images of vertical sections of rat retinas (control group). (E-H) Digital images of vertical sections of RCS rat retinas (degeneration group). The ONL thickness was the same between the control and degeneration groups at P15, but was thinner at P30 in the RCS rats, in which photoreceptor cells decreased in number at P60 and were virtually nonexistent at P90. Meanwhile, the INL remained almost unchanged. Red arrows indicate the fibrotic glial seal of Müller cells. ONL, outer nuclear layer; OPL, outer plexiform layer; INL, inner nuclear layer; IPL, inner plexiform layer; GCL, ganglion cell layer; FGSL, fibrotic glial seal layer. Scale: one bar, $10 \mu \mathrm{m}$.
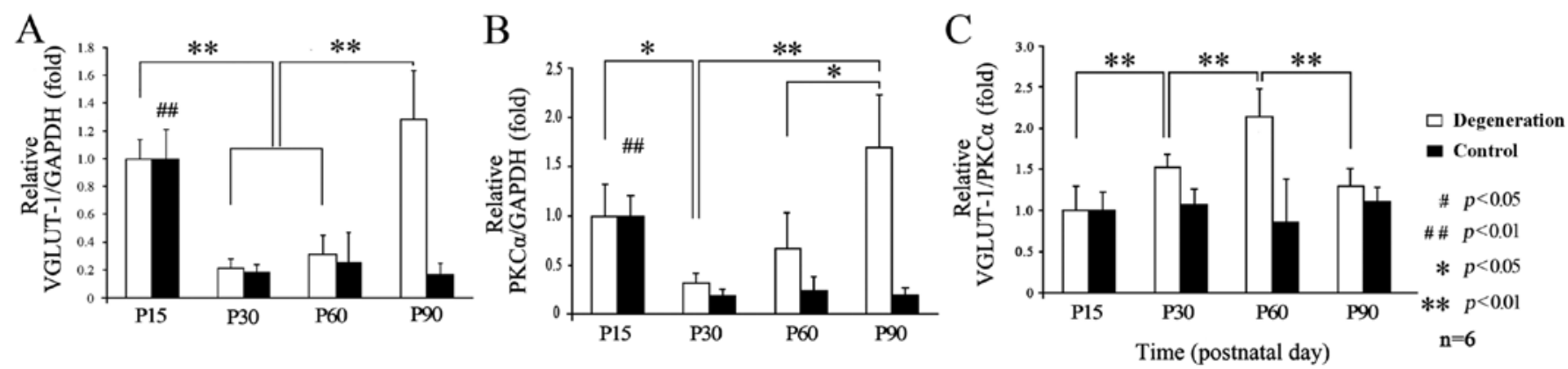

Figure 2. qPCR analysis of the relative expression levels of VGLUT-1 and PKC $\alpha$ mRNA. (A) Relative expression of VGLUT-1/GAPDH at each time-point The level of VGLUT-1 mRNA was the highest at P15 in the control group, compared with that at P30, P60 and P90 (n=6/group; $p<0.01$ ). In the RCS rats, the VGLUT-1 level was the lowest at P30, and it increased significantly from P30 to P90 ( $<<0.01$ ). (B) Relative expression of PKC $\alpha /$ GAPDH at each time-point Expression levels of PKC $\alpha$ mRNA showed similar trends as VGLUT-1, but the PKC $\alpha$ expression decreased significantly at P30 compared with that at P15 in the RCS rats. (C) Relative expression of VGLUT-1/PKC $\alpha$ at each time-point. Relative expression of VGLUT-1 mRNA was constant and showed no significant differences at any time-point in the control group. Expression of VGLUT-1 relative to PKC $\alpha$ increased gradually from P15 to P60 in the RCS rats (p<0.01), followed by a decrease at $\mathrm{P} 90(\mathrm{p}<0.01)$.

P15 between RCS and control rats, although different tendencies existed in both groups. In the control group, VGLUT-1 expression reached a peak at P15 (Fig. 2A), decreased rapidly at
P30, and then stabilized to a lower level. By contrast, VGLUT-1 expression in the RCS rats decreased slightly at P30, then gradually increased at P60, and increased rapidly (as much 


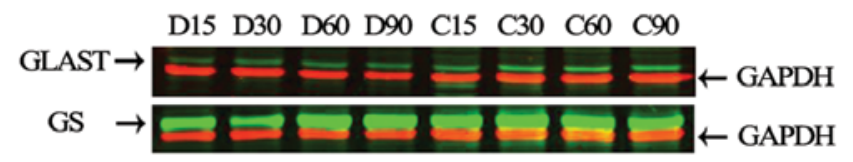

Figure 3. Western blot analysis of GLAST and GS by Odyssey infrared imaging of the retinas of each group ( $n=6 /$ group). Representative western blot analyses for GLAST (60 kDa), GS (42 kDa), and GAPDH (36 kDa) are shown. Red blots are GAPDH bands; green blots in each membrane represent GLAST and GS bands. D15, D30, D60 and D90 represent the RCS rats at P15, P30, P60 and P90, respectively. C15, C30, C60 and C90 represent the control group at $\mathrm{P} 15, \mathrm{P} 30, \mathrm{P} 60$ and $\mathrm{P} 90$, respectively.

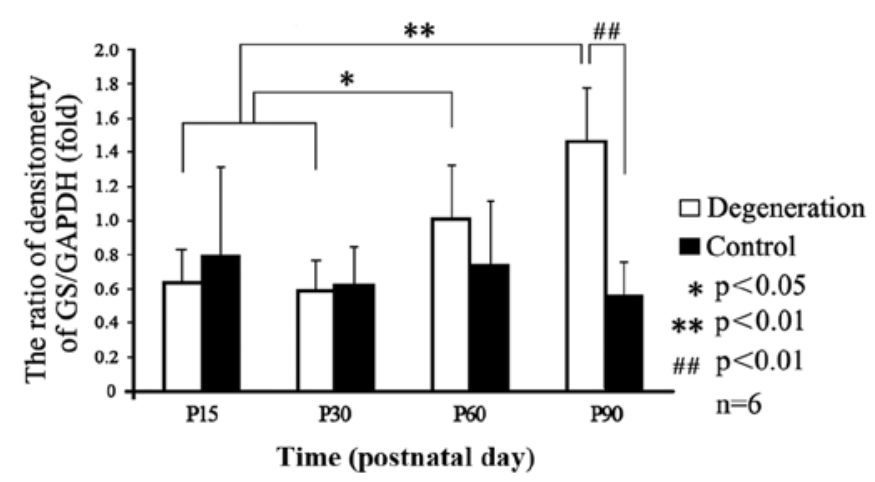

Figure 4. Densitometric analysis of GS expression. Data are presented as the means \pm SE ( $n=6 /$ group). GS expression was constant in the control group a different time-points. In the RCS rats, there was a significant increase from $\mathrm{P} 30$ to P90. The GS protein level in the RCS rats reached a peak value at P90, compared with the control group at the same time-point $(\mathrm{p}<0.01)$.

as 3-fold) at P90. Differences were also seen in the PKC $\alpha$ expression tendencies (Fig. 2B). In the control group, the level of VGLUT-1 relative to PKC $\alpha$ remained unchanged at all timepoints (Fig. 2C), while in the RCS rats, it reached a peak at P60 and then decreased at P90.

Transport and conversion capacity of glutamate. Western blot analysis was used to analyze the expression levels of GLAST and GS. Odyssey infrared imaging showed that the GLAST levels did not change significantly in either group at any timepoint (Fig. 3). However, analysis of GS expression relative to that of GAPDH showed a time-dependent increase in the control group (Figs. 3 and 4), while it gradually increased from $\mathrm{P} 15$ to its peak value at $\mathrm{P} 90(\mathrm{p}<0.05)$ in the degeneration group.

\section{Discussion}

Glutamate is involved in neuronal survival during postnatal development of the retina $(17,18)$ and plays a key role in the formation of retinal synaptic circuitry (18-21). In rats, the normal death periods of bipolar cells and rods extend from birth to $\mathrm{P} 4$. Subsequently, there is a gradual decrease in the incidence of cell death, and the degeneration of bipolar cells continues until P48 (22). The apoptosis phase of photoreceptor cells in the normal rat retina occurs between P12 and P72, peaking at P23 (23). These occurrences lead to decreasing VGLUT-1 and $\mathrm{PKC} \alpha$ levels in normal and degenerating rat retinas, consistent with our data showing that the expression of VGLUT-1 and PKC $\alpha$ was significantly decreased at P30 compared to P15.
It is known that retinal degeneration in RCS rats involves initial rod photoreceptor loss $(24,25)$. A very high percentage of inner retinal neurons remained histologically intact, although loss of cells in all retinal layers was found (8). The bipolar cells in the inner plexiform layer (IPL) gradually became the predominant cells and became the main source releasing glutamate following retinal degeneration (25). The number of rod bipolar cells in the IPL is relatively stable during retinal degeneration, due to their characteristics of terminal differentiation and incapability of proliferation. Since PKC $\alpha$ exists mainly in bipolar cells in the retina, we indirectly detected the number of bipolar cells in the INL by detecting the levels of PKC $\alpha$. VGLUT-1 was specifically localized to photoreceptor and bipolar cell terminals in the retina (26) and accounts for the ability of excitatory neurons to release glutamate by exocytosis (27). VGLUT-1 exhibits the glutamate levels released and stored in the whole retina. Therefore, we detected the ratio of VGLUT-1 to PKC $\alpha$ to indirectly show whether or not the glutamate levels released and stored in the whole retina had changed. Our data demonstrated that the ONL thickness decreased, while the ratio of VGLUT-1 to PKC $\alpha$ increased during retinal degeneration up to P60. These results indicate that the percentage of living rod bipolar cells increased, while the bipolar cells simultaneously became the main glutamatereleasing neurons in the retina during retinal degeneration. Thus, the ability of bipolar cells to release and store glutamate increased.

The relative level of VGLUT-1 to PKC $\alpha$ reached a peak at P60, but subsequently decreased at P90, which indicated that glutamate release increases gradually until the middle phase and decreases during the latter phases of retinal degeneration. These findings may be helpful in clarifying a contradiction regarding glutamate changes during retinal degeneration. Certain studies have reported that glutamate increases (28), whereas others have reported a decreasing trend during later periods of degeneration (29). In this study, at the late stage of retinal degeneration, the glutamate-releasing neurons in the retina were mainly bipolar cells. Therefore, the decrease of this ratio demonstrated that the release of glutamate from bipolar cells to ganglion cells decreased, which suggests the deafferentation of ganglion cells.

Glutamate toxicity has been demonstrated in both inner retinal cells and photoreceptor terminals $(15,16)$. Since there is no apparent extracellular conversion of glutamate, retinal tissues require a powerful uptake mechanism capable of quickly removing extracellular glutamate to protect itself. Müller cells play a critical role in the inactivation of glutamate released by glutamatergic neurons, since they have a high affinity for $\mathrm{Na}^{+}$-linked transporters that take up glutamate (30). In addition, unprotected neurons in culture may be killed by even lower concentrations of glutamate in the medium (31-33).

Glutamate uptake is accomplished by glutamate transporter proteins located in the plasma membranes of retinal Müller cells $(34,35)$. GLAST has been described in retinal Müller, astrocyte, and RPE cells in rats $(36,37)$ and the consequences induced by its absence from neuronal elements have also been reported (38). Our data show that GLAST expression levels remain unchanged throughout retinal degeneration in RCS rats, which is different from previous reports (28). We hypothesize that such a discrepancy likely arises from the different animal 
models and infrared imaging systems used. For instance, the probing of the target and reference proteins simultaneously in a particular sample indicates blots at $\sim 60 \mathrm{kDa}$, without GLAST multimeric forms in our results to abate any possible measurement errors. In addition, the retinal degeneration mouse is a rapid retinal degeneration model, unlike the RCS rat, which is a slow degeneration animal model. Despite these differences, our results indicate that glutamate uptake decreases (with GLAST levels remaining unchanged) lead to inefficient extracellular glutamate transport into Müller cells and, consequently, induce the accumulation of glutamate in the extracellular space, resulting in toxicity to living neurons.

In our study, GS expression remained constant in the control group at all time-points, while differences in the RCS rats appeared from P30 onwards, with a significant increase at P90. These findings are consistent with results of a previous study, in which GS increased during the terminal stages of retinal degeneration (28). In our study, the GS expression pattern was similar to that of VGLUT-1 from P30 to P90. Increased GS expression does not result from Müller cell proliferation or from any concentration change in the RCS retinas (28). By P15 and P30, the conversion of glutamate into glutamine via GS activity in Müller cells was efficient; however, from P60 to P90, the level of GS in Müller cells was gradually increased and the glutamate balance was eventually disrupted, suggesting the existence of glutamate conversion enhanced within Müller cells. In general, expression of GS is regulated by glutamate (39). When the major glutamate-releasing population of neurons and photoreceptors degenerate, GS expression in Müller cells is reduced (40-42). However, in the present study, the number of glutamatergic neurons reduced, while the level of GS increased, indicating that intracellular glutamate likely increases in Müller cells.

In conclusion, our results demonstrate that VGLUT-1 expression is high at P15 in both RCS and control rats. However, a gradual increase in VGLUT-1 levels, accompanied by photoreceptor degeneration, was observed after P30, while the relative expression of VGLUT-1 to PKC $\alpha$ levels increased up to P60, and decreased in P90, suggesting that glutamate release and storage gradually increases until the middle stage of retinal degeneration, but it decreases in the latter stage of retinal degeneration. Finally, GLAST expression levels remained unchanged, while GS expression increased gradually during the early stages and reached peak levels during the latter stages of retinal degeneration.

\section{Acknowledgements}

This study was supported by the National Basic Research Program of China (973 program) (Grant no. 2007CB512203). The authors thank Jianrong He for technical assistance, and Lifeng Chen and Yaochen Li for their suggestions and discussion on the manuscript.

\section{References}

1. Olney JW: The toxic effects of glutamate and related compounds in the retina and the brain. Retina 2: 341-359, 1982.

2. Sullivan LS and Daiger SP: Inherited retinal degeneration: exceptional genetic and clinical heterogeneity. Mol Med Today 2: 380-386, 1996.
3. D'Cruz PM, Yasumura D, Weir J, et al: Mutation of the receptor tyrosine kinase gene Mertk in the retinal dystrophic RCS rat. Hum Mol Genet 9: 645-651, 2000.

4. LaVail MM: Photoreceptor characteristics in congenic strains of RCS rats. Invest Ophthalmol Vis Sci 20: 671-675, 1981.

5. LaVail MM, Sidman RL and Gerhardt CO: Congenic strains of RCS rats with inherited retinal dystrophy. J Hered 66: 242-244, 1975.

6. Strettoi E, Porciatti V, Falsini B, Pignatelli V and Rossi C: Morphological and functional abnormalities in the inner retina of the rd/rd mouse. J Neurosci 22: 5492-5504, 2002.

7. Strettoi E and Pignatelli V: Modifications of retinal neurons in a mouse model of retinitis pigmentosa. Proc Natl Acad Sci USA 97: 11020-11025, 2000.

8. Santos A, Humayun MS, Juan Ed, et al: Preservation of the inner retina in retinitis pigmentosa. A morphometric analysis. Arch Ophthalmol 115: 511-515, 1997.

9. Jones BW and Marc RE: Retinal remodeling during retinal degeneration. Exp Eye Res 81: 123-137, 2005.

10. Marc RE and Jones BW: Retinal remodeling in inherited photoreceptor degenerations. Mol Neurobiol 28: 139-147, 2003.

11. Chen ZS, Yin ZQ, Chen S and Wang SJ: Electrophysiological changes of retinal ganglion cells in Royal College of Surgeons rats during retinal degeneration. Neuroreport 16: 971-975, 2005.

12. Kalloniatis M and Tomisich G: Amino acid neurochemistry of the vertebrate retina. Prog Retin Eye Res 18: 811-866, 1999.

13. Babai N, Morgans CW and Thoreson WB: Calcium-induced calcium release contributes to synaptic release from mouse rod photoreceptors. Neuroscience 165: 1447-1456, 2010.

14. Yang XL: Characterization of receptors for glutamate and GABA in retinal neurons. Prog Neurobiol 73: 127-150, 2004.

15. Karl MO, Hayes S, Nelson BR, Tan K, Buckingham B and Reh TA: Stimulation of neural regeneration in the mouse retina. Proc Natl Acad Sci USA 105: 19508-19513, 2008.

16. Shen W, Li S, Chung SH and Gillies MC: Retinal vascular changes after glial disruption in rats. J Neurosci Res 88: 1485-1499, 2010.

17. Nicoletti F, Bruno V, Copani A, Casabona G and Knopfel T: Metabotropic glutamate receptors: a new target for the therapy of neurodegenerative disorders? Trends Neurosci 19: 267-271, 1996.

18. Phillips MJ, Otteson DC and Sherry DM: Progression of neuronal and synaptic remodeling in the rd10 mouse model of retinitis pigmentosa. J Comp Neurol 518: 2071-2089, 2010.

19. Cuenca N, Pinilla I, Sauve Y and Lund R: Early changes in synaptic connectivity following progressive photoreceptor degeneration in RCS rats. Eur J Neurosci 22: 1057-1072, 2005.

20. Zhang J and Diamond JS: Subunit- and pathway-specific localization of NMDA receptors and scaffolding proteins at ganglion cell synapses in rat retina. J Neurosci 29: 4274-4286, 2009.

21. Jarsky T, Tian M and Singer JH: Nanodomain control of exocytosis is responsible for the signaling capability of a retinal ribbon synapse. J Neurosci 30: 11885-11895, 2010.

22. Vecino E, Hernandez M and Garcia M: Cell death in the developing vertebrate retina. Int J Dev Biol 48: 965-974, 2004.

23. Vogel $\mathrm{M}$ and Moller K: Cellular decay in the rat retina during normal post-natal development: a preliminary quantitative analysis of the basic endogenous rhythm. Albrecht Von Graefes Arch Klin Exp Ophthalmol 212: 243-260, 1980.

24. Jones BW, Watt CB and Marc RE: Retinal remodelling. Clin Exp Optom 88: 282-291, 2005.

25. Marc RE, Jones BW, Anderson JR, et al: Neural reprogramming in retinal degeneration. Invest Ophth Vis Sci 48: 3364-3371, 2007.

26. Gong J, Jellali A, Mutterer J, Sahel JA, Rendon A and Picaud S: Distribution of vesicular glutamate transporters in rat and human retina. Brain Res 1082: 73-85, 2006.

27. Fremeau RT, Kam K, Qureshi T, et al: Vesicular glutamate transporters 1 and 2 target to functionally distinct synaptic release sites. Science 304: 1815-1819, 2004.

28. Delyfer MN, Forster V, Neveux N, Picaud S, Leveillard T and Sahel JA: Evidence for glutamate-mediated excitotoxic mechanisms during photoreceptor degeneration in the rd1 mouse retina. Mol Vis 11: 688-696, 2005

29. Okada M, Okuma Y, Osumi Y, Nishihara M, Yokotani K and Ueno H: Neurotransmitter contents in the retina of RCS rat. Graefes Arch Clin Exp Ophthalmol 238: 998-1001, 2000.

30. Garlin AB, Sinor AD, Sinor JD, Jee SH, Grinspan JB and Robinson MB: Pharmacology of sodium-dependent high-affinity L-[3H]glutamate transport in glial cultures. J Neurochem 64: 2572-2580, 1995. 
31. Minami M, Oku H, Okuno T, Fukuhara M and Ikeda T: High infusion pressure in conjunction with vitreous surgery alters the morphology and function of the retina of rabbits. Acta Ophthalmol Scan 85: 633-639, 2007.

32. Sedaghat K, Finkelstein DI and Gundlach AL: Effect of unilateral lesion of the nigrostriatal dopamine pathway on survival and neurochemistry of parafascicular nucleus neurons in the rat - evaluation of time-course and LGR8 expression. Brain Res 1271: 83-94, 2009.

33. Friedman LK and Segal M: Early exposure of cultured hippocampal neurons to excitatory amino acids protects from later excitotoxicity. Int J Dev Neurosci 28: 195-205, 2010.

34. Ward MM, Jobling AI, Kalloniatis M and Fletcher EL: Glutamate uptake in retinal glial cells during diabetes. Diabetologia 48 : 351-360, 2005

35. Namekata K, Harada C, Kohyama K, Matsumoto Y and Harada T: Interleukin-1 stimulates glutamate uptake in glial cells by accelerating membrane trafficking of $\mathrm{Na}^{+} / \mathrm{K}^{+}$-ATPase via actin depolymerization. Mol Cell Biol 28: 3273-3280, 2008.

36. Otori Y, Shimada S, Tanaka K, Ishimoto I, Tano Y and Tohyama M: Marked increase in glutamate-aspartate transporter (GLAST/GluT-1) mRNA following transient retinal ischemia. Mol Brain Res 27: 310-314, 1994.
37. Derouiche A and Rauen T: Coincidence of L-glutamate/Laspartate transporter (GLAST) and glutamine synthetase (GS) immunoreactions in retinal glia: evidence for coupling of GLAST and GS in transmitter clearance. J Neurosci Res 42: 131-143, 1995.

38. Lehre KP, Davanger S and Danbolt NC: Localization of the glutamate transporter protein GLAST in rat retina. Brain Res 744: 129-137, 1997.

39. Shen F, Chen B, Danias J, et al: Glutamate-induced glutamine synthetase expression in retinal Müller cells after short-term ocular hypertension in the rat. Invest Ophthalmol Vis Sci 45: 3107-3112, 2004.

40. Germer A, Jahnke C, Mack A, Enzmann V and Reichenbach A: Modification of glutamine synthetase expression by mammalian Müller (glial) cells in retinal organ cultures. Neuroreport 8: 3067-3072, 1997.

41. Shen X and Xu G: Role of IL-1beta on the glutamine synthetase in retinal Muller cells under high glucose conditions. Curr Eye Res 34: 727-736, 2009.

42. Jablonski MM, Tombran-Tink J, Mrazek DA and Iannaccone A: Pigment epithelium-derived factor supports normal Müller cell development and glutamine synthetase expression after removal of the retinal pigment epithelium. Glia 35: 14-25, 2001. 